\title{
PCBs in the Arctic atmosphere: determining important driving forces using a global atmospheric transport model
}

\author{
Carey L. Friedman ${ }^{1, \mathrm{a}}$ and Noelle E. Selin ${ }^{2}$ \\ ${ }^{1}$ Center for Global Change Science, Massachusetts Institute of Technology, Cambridge, Massachusetts, USA \\ ${ }^{2}$ Institute for Data, Systems, and Society and Department of Earth, Atmospheric and Planetary Sciences, \\ Massachusetts Institute of Technology, Cambridge, Massachusetts, USA \\ ${ }^{a}$ now at: Corning School of Ocean Studies, Maine Maritime Academy, Castine, Maine, USA \\ Correspondence to: Carey L. Friedman (carey.friedman@mma.edu)
}

Received: 21 August 2015 - Published in Atmos. Chem. Phys. Discuss.: 5 November 2015

Revised: 1 March 2016 - Accepted: 1 March 2016 - Published: 16 March 2016

\begin{abstract}
We present a spatially and temporally resolved global atmospheric polychlorinated biphenyl (PCB) model, driven by meteorological data, that is skilled at simulating mean atmospheric PCB concentrations and seasonal cycles in the Northern Hemisphere midlatitudes and mean Arctic concentrations. However, the model does not capture the observed Arctic summer maximum in atmospheric PCBs. We use the model to estimate global budgets for seven PCB congeners, and we demonstrate that congeners that deposit more readily show lower potential for long-range transport, consistent with a recently described "differential removal hypothesis" regarding the hemispheric transport of PCBs. Using sensitivity simulations to assess processes within, outside, or transport to the Arctic, we examine the influence of climateand emissions-driven processes on Arctic concentrations and their effect on improving the simulated Arctic seasonal cycle. We find evidence that processes occurring outside the Arctic have a greater influence on Arctic atmospheric PCB levels than processes that occur within the Arctic. Our simulations suggest that re-emissions from sea ice melting or from the Arctic Ocean during summer would have to be unrealistically high in order to capture observed temporal trends of PCBs in the Arctic atmosphere. We conclude that midlatitude processes are likely to have a greater effect on the Arctic under global change scenarios than re-emissions within the Arctic.
\end{abstract}

\section{Introduction}

Polychlorinated biphenyls (PCBs) are chemicals that were manufactured for industry beginning in the 1930s (Breivik et al., 2002). Since the peak of their manufacture and use, PCBs have been shown to be toxic, bioaccumulative, persistent, and to travel long distances in the environment. Consequently, their production was banned by national actions as early as the 1970s. Under the global Stockholm Convention, which entered into force in 2004, parties committed to eliminate PCB production. PCBs continue to pose health risks, however, because of their recalcitrance and ability to cycle through environmental phases. Indigenous peoples and top marine predators in the Arctic are especially exposed to health risks from PCBs. Because of their high lipophilicity, PCBs are readily accumulated by marine mammals, and the traditional diets of the Arctic indigenous rely heavily on these animals. The surprisingly high body burdens in indigenous populations, given that PCBs generally were not used in the region, were first documented in the literature decades ago (e.g., Dewailly et al., 1989). However, there remain important uncertainties about the driving factors of Arctic concentrations, particularly in the context of reduced primary emissions and changing climate. Here, we use a chemical transport model to assess factors affecting the long-range atmospheric transport of PCBs to the Arctic.

Evidence of long-range atmospheric PCB transport to the Arctic from the Northern Hemisphere midlatitudes, where their manufacture and use were concentrated, has been well-documented (e.g., Hung et al., 2001, 2005, 2010). 
The warmer temperatures of the midlatitudes facilitate $\mathrm{PCB}$ volatilization and their subsequent transport via the atmosphere to the Arctic. Several hypotheses have been proposed to mechanistically describe the transport process and the observed global fractionation of PCBs. The most well known is the "global distillation hypothesis" (Wania and Mackay, 1993, 1996), whereby PCBs and other persistent organic pollutants (POPs) fractionate globally along a latitudinal temperature gradient depending on their volatility, similar to a gas chromatographic separation. A relatively new hypothesis, the "differential removal hypothesis", expands on the global distillation hypothesis with an interpretation of observational and modeling data that accounts for the correlation between latitudinal temperature and remoteness. This latter hypothesis proposes that the observed global fractionation of PCBs is due primarily to different loss rates that act along a gradient of remoteness from emission sources rather than temperature differences (von Waldow et al., 2010).

Whether or not remoteness is the primary driver of PCB transport compared to temperature fractionation, as suggested by the differential removal hypothesis, temperature nevertheless plays a strong role in determining the environmental behavior of PCBs globally. Higher temperatures lead to greater fractions of PCBs in the atmospheric gas phase versus the particle phase (which alters overall loss rates) and a shift in partitioning between other environmental media (including increased fluxes from surface media to the atmosphere). Temperature can also affect emissions, including both primary and secondary emissions (i.e., revolatilization of previously deposited PCBs from surface phases) and degradation rates (Hansen et al., 2015; Lamon et al., 2009; Wornschimmel et al., 2013). For this reason, the impact of global climate change on the environmental cycling of PCBs has received much interest. Results from a number of recent modeling studies collectively suggest that predicted climate change will affect atmospheric PCBs by roughly a factor of 2 (Hansen et al., 2015; Lamon et al., 2009; Wornschimmel et al., 2013). Whether concentrations increase or decrease depends on the congener modeled, the model used, and model inputs. In general, however, previous studies have shown that predicted changes in emissions will have a stronger impact on future concentrations than climate and that uncertainties in model inputs are substantial enough to make interpretation of climate impact data challenging. For example, Wornschimmel et al. (2013) found that atmospheric concentrations of PCB 153 increased by a factor of 1.8 between 2010 and 2100 using the BETR-Research model, but they estimated uncertainties in absolute predicted concentrations within a factor of 5 to 10. Despite uncertainties, studies of global and hemispheric atmospheric PCBs in a future climate generally identify temperature as a key driving factor.

The mechanisms affecting the climate-driven variability of PCB concentrations in the Arctic, however, are less certain. In the Arctic, temperatures are increasing at rates faster than the global average and sea ice coverage is declining rapidly.
The uncertainty in mechanisms of PCB variability due to climatic drivers primarily results from a lack of empirical data characterizing the behavior of PCBs in Arctic surface media, such as snow, ice, and seawater, and their interaction with the atmosphere. Conclusions from existing modeling studies and observational data can be contradictory. For example, Ma et al. (2011) suggest that slight increases in atmospheric PCB concentrations at the Alert (Canada) and Zeppelin (Svalbard, Norway) from the early to mid-2000s are likely due to revolatilization of PCBs from melting sea ice and the Arctic Ocean. Zhao et al. (2015) propose that step change increases in Arctic atmospheric PCBs in recent years coincide with lower sea ice coverage. In contrast, Gioia et al. (2008) argued that PCBs are under a net deposition regime across the North Atlantic and Arctic oceans; i.e., PCBs are being absorbed by the Arctic Ocean rather than volatilizing. Sobek and Gustafsson (2014) also presented evidence of the Arctic Ocean acting mainly as a sink rather than a source of PCBs to the atmosphere. They constructed a budget of PCBs in the Arctic Ocean and concluded that sea ice and surface waters contained insignificant masses of PCBs compared to other compartments. Lastly, studies focusing on the impact of surface snow and/or ice on atmospheric concentrations have shown that snow and ice can increase atmospheric concentrations relative to no or less snow/ice cover for volatile compounds (Hansen et al., 2006; Stocker et al., 2007; Wornschimmel et al., 2013). In summary, the role of typical Arctic surface media on atmospheric concentrations of POPs is unclear, even in the absence of rapid change.

Here, we use information about the spatial and temporal variability of midlatitude and Arctic PCB concentrations to constrain the relative importance of climate-driven processes to Arctic PCB concentrations. To do this, we construct a spatially and temporally resolved PCB model, driven by meteorological data, that can reproduce global measured atmospheric PCB concentrations; then we manipulate the model to see how changing specific environmental and chemical parameters impacts the model's ability to reproduce historical measurements in the Arctic. We use this comparison to examine the relative importance of local versus global PCB sources and dynamics to Arctic atmospheric PCB concentrations. We first evaluate the new model by comparing simulated concentrations to measurements from 1991 to 2010, and use the model to calculate global and Arctic budgets for the International Council for the Exploration of the Sea (ICES) seven PCB congeners (CBs 28, 52, 101, 118, 138, 153 , and 180). We then conduct sensitivity simulations for CB 28 by manipulating model parameters associated with three distinct spatial categories of Arctic drivers to determine which factors controlling PCBs have the greatest impact on Arctic concentrations and seasonal cycles. We conclude by discussing implications of our work for studies of PCB concentrations under future climate. 


\section{Methods}

\subsection{GEOS-Chem PCB model}

The GEOS-Chem POP model has been previously developed and applied to PAHs (Friedman et al., 2014a, b; Friedman and Selin, 2012); here, we extend it to address PCBs. The GEOS-Chem POP simulation (v9-01-03) includes oxidation of gas-phase species by hydroxyl radical $(\mathrm{OH}$; scaled for diurnal variation), wet and dry deposition of both gas and particle phases, and temperature-dependent partitioning between the gas and particle phases. For PCBs, we neglect particle-phase oxidation, as there is no evidence in the literature that this is an important process. We partition PCBs to one bulk organic matter $(\mathrm{OM})$ phase, which combines the two different types of particle phases used previously in simulating PAHs: an OM phase and a black carbon (BC) phase. While PAHs have been shown to adsorb strongly to BC in the field (e.g., Accardi-Dey and Gschwend, 2002; Arp et al., 2008; Lohmann et al., 2005), and modeling studies have suggested PAH association with $\mathrm{BC}$ particles can explain long-range transport (LRT) patterns (Friedman et al., 2014a), literature from contaminated marine sediment studies suggests enhanced sorption to $\mathrm{BC}$ occurs primarily for non-ortho-substituted PCB congeners (i.e., those that assume a planar conformation; Cornelissen et al., 2005; Koelmans et al., 2006), which we do not simulate here. Furthermore, in contrast to PAHs, there is little evidence directly from the atmospheric literature to suggest PCBs show enhanced sorption to BC compared to OM (Arp et al., 2008). Therefore, the model assumes PCBs partition between the gas and particle phase following their octanol-air partition coefficients ( $K_{\mathrm{OA}}$; see Supplement for details). A separate $\mathrm{NO}_{X}-\mathrm{O}_{X-}$ hydrocarbon-aerosol simulation of GEOS-Chem (v9-01-02) is used to generate monthly mean concentrations of $\mathrm{OM}$ and $\mathrm{OH}$, which are archived and read into the POP simulation as input. OM particles to which PCBs associate convert from hydrophobic to hydrophilic with a lifetime of 1.2 days (Park et al., 2003); this serves to increase the efficiency of particlephase PCB wet scavenging over time. We use the "high" annual PCB emissions inventory from Breivik et al. (2007), compiled on a national basis and spatially allocated on a $1^{\circ} \times 1^{\circ}$ grid globally, as input emissions from 1930 to 2010 . Primary emissions depend on ambient temperature following the van't Hoff equation:

$E_{T_{2}}=E_{T_{1}} \times \exp \left[\frac{-\Delta H}{R} \times\left(\frac{1}{T_{2}}-\frac{1}{T_{1}}\right)\right]$,

where $E_{T_{2}}$ is the emissions rate $\left(\mathrm{kg} \mathrm{s}^{-1}\right)$ at the ambient surface air temperature $T_{2}(\mathrm{~K}), E_{T_{1}}$ is the emissions rate $\left(\mathrm{kg} \mathrm{s}^{-1}\right)$ given by the emissions inventory at an assumed mean global surface temperature $\left(T_{1}\right)$ of $288 \mathrm{~K}, \Delta H$ is the internal phase transfer energy $\left(\mathrm{J} \mathrm{mol}^{-1}\right)$ for the transfer from the gas phase to the particle phase, and $R$ is the gas constant $\left(\mathrm{J} \mathrm{K}^{-1} \mathrm{~mol}^{-1}\right)$. For simulated years 1930 (the start of PCB production and hence emissions; Breivik et al., 2007) to 1978, we use assimilated meteorology from the NASA Global Modeling and Assimilation Office (GMAO) data set degraded to $6 \mathrm{~h}$ temporally, $4^{\circ} \times 5^{\circ}$ horizontally, and 47 levels vertically. The GEOS5 product includes data from years 2004-2012; hence, we repeat a subset of meteorological years (2006-2008) for the 1930-1978 "spin-up" of the model. For simulated years 1979-2010 we use the NASA GMAO Modern-Era Retrospective analysis for Research and Applications (MERRA) data set, which is consistent over the $30+$ year historical period. MERRA data are also downgraded from their native resolution to fit the model resolution. GEOS5 data are averaged at 3 or $6 \mathrm{~h}$ intervals, while MERRA data are averaged at 3 or $1 \mathrm{~h}$ intervals, depending on the variable. The native spatial resolution of both GEOS5 and MERRA products is $1 / 2^{\circ} \times 2 / 3^{\circ}$ with 72 vertical levels.

PCB simulations include an improved mechanism in the GEOS-Chem POP model for surface-atmosphere interactions. PCB dynamics in surface compartments, which include soils, vegetation, lakes, oceans, and snow/ice, are parameterized with level IV fugacity box models embedded within GEOS-Chem. The parameterization of each surface compartment and methods for estimating the fractional coverage of a grid box by a given surface medium are described in detail in the Supplement, with references therein, along with tabulations of physicochemical constants used for each process and congener, but we provide a brief summary here.

The fraction of soil coverage within a grid box is estimated by subtracting the fraction of snow from the fraction of land, which are both provided by the MERRA data set. Once deposited, PCBs are assumed to distribute within the top $5 \mathrm{~cm}$. Sorption to soils is dependent on a soil-air partition coefficient $\left(K_{\mathrm{SA}}\right)$, which in turn depends on the fraction of organic carbon $(\mathrm{OC})$ in the soil $\left(f_{\mathrm{OC}}\right)$ and $K_{\mathrm{OA}}$. The $f_{\mathrm{OC}}$ is generated with a version of the CASA biogeochemical model previously coupled to GEOS-Chem (Smith-Downey et al., 2010) at latitudes between $60^{\circ} \mathrm{N}$ and $60^{\circ} \mathrm{S}$; at the poles, a mean Arctic tundra lowlands soil carbon content $\left(15.1 \mathrm{~kg} \mathrm{C} \mathrm{m}^{-2}\right)$ from the organic-enriched surface horizon (Ping et al., 2008) is used to estimate $f_{\mathrm{OC}}$, as $f_{\mathrm{OC}}$ is not well defined by CASA in seasonally ice-covered regions. Losses of PCBs from soils include re-emissions, degradation, runoff, and leaching. Transfer of PCBs to soils can come from direct atmospheric deposition, from snow/ice melt, from vegetative litterfall, or from a fraction of wet deposition that has washed off vegetation. Additional citations used in creating the soil module include Mackay (2001), Mackay and Paterson (1991), Potter et al. (1993), and Ribes et al. (2003).

The fraction of a grid box covered in vegetation is estimated by multiplying the fraction of soil by a greenness index (values between 0 and 1), provided by the meteorological data. Deposition to vegetation includes all dry deposition and $10 \%$ of wet deposition. The other $90 \%$ of wet deposition is passed directly to soils (following Cousins and Mackay, 2000). All vegetation is assumed to consist of leaves 
having a surface thickness of $2 \times 10^{-6} \mathrm{~m}$ and an internal reservoir of $0.01 \mathrm{~m}$ thickness, and a total vegetation volume in a grid box is estimated by multiplying total leaf thickness by the leaf area index. The sequestration of PCBs in vegetation is controlled by both the air-water partition coefficient $\left(K_{\mathrm{AW}}\right)$ and the $K_{\mathrm{OA}}$. PCB losses from vegetation include re-emissions, litter loss, and degradation. Citations used in creating the vegetation module include Cousins and Mackay (2000, 2001), Mackay (2001), and Mackay and Paterson (1991).

The behavior of PCBs in freshwater and seawater is parameterized similarly. The fraction of lake in a grid box is given by the meteorological data, while the fraction of open ocean is estimated by subtracting the fraction of sea ice from the total fraction of ocean (both also provided by meteorological data). Deposition to both comes directly from the atmosphere or from melting snow/ice. Lakes are assumed to be $10 \mathrm{~m}$ deep while oceans are assumed to be $1000 \mathrm{~m}$ deep. We assume a volume fraction of $5 \times 10^{-6}$ for particles in freshwater, with $20 \%$ OC content. In seawater, we assume a particle volume fraction of $1 \times 10^{-6}$ also with $20 \%$ OC content. Sorption to particles is governed by the $K_{\mathrm{OA}}$. Losses from both include re-emissions, degradation, and deposition to sediments with particles. Literature used in creating the lake and ocean modules includes Mackay (2001), Mackay and Paterson (1991), and Schwarzenbach et al. (2003).

The fraction of snow/ice in a grid box is estimated by adding the fractions of snow, sea ice, and land ice (provided by meteorological data; see http://gmao.gsfc.nasa. gov/products/documents/MERRA_File_Specification.pdf for more details). PCBs are deposited directly from the atmosphere to the ice/snowpack. Sorption of PCBs in snow depends on a snow surface-air adsorption coefficient $\left(K_{\mathrm{CA}}\right)$, which in turn depends on the density of the snow and the temperature-dependent specific snow surface area (surface area per unit mass). Losses from snow include re-emissions, degradation, meltwater runoff, and particle flushing. Literature used in creating the snow/ice module includes Abraham and Al-Hussaini (2005), Daly and Wania (2004), Hansen et al. (2006), Roth et al. (2004), and Stocker et al. (2007).

Degradation reaction rate constants in all environmental media are temperature dependent following the Arrhenius equation. Surface media half-lives and molar masses were chosen to be consistent with those used in other modeling studies (Li et al., 2003; Mackay et al., 2006). Activation energies were also chosen to be consistent with previous PCB modeling studies (Gouin et al., 2013; Lamon et al., 2009). Details are presented in the Supplement.

\subsection{Model evaluation}

We evaluate the performance of the model by comparing simulated interannual mean total (gas plus particle phase) concentrations to measured total concentrations at specific sites globally, for all ICES congeners. We then compare the sim- ulated total versus measured total seasonal average concentrations globally for CBs 28 and 153 from 1991 to 2010. We chose these two congeners for seasonal comparisons because they have been the focus of previous PCB work (e.g., Lamon et al., 2009) and because they span a wide range of volatilities. Finally, we compare the monthly mean total concentrations and long-term monthly averages of these two congeners for sites representative of model skill at Arctic and remote midlatitude measurement stations: Zeppelin (Norway) and Burnt Island (Canada), respectively. We choose Zeppelin as an Arctic representative site because of its extensive monitoring history (from 1998 onward), its high Arctic location $\left(80^{\circ} \mathrm{N}\right)$, and because time series data from the only other station at such a high latitude (Alert, Canada) were affected by a laboratory switch in 2002 (Su et al., 2011). We choose Burnt Island because of its long monitoring history (since 1992), because its location is more distant from the midlatitude/Arctic boundary $\left(66^{\circ} \mathrm{N}\right)$ than European stations with similarly long monitoring histories, and because data were available for both CB 28 and 153 .

\subsection{Sensitivity simulations}

We conduct 10 sensitivity simulations in which individual model processes are either removed or altered to assess their impact on mean simulated Arctic PCB 28 concentrations and seasonal cycles from 1992 to 2009 . These 10 sensitivity simulations are grouped into three general "Arctic driver" categories, depending on what was altered in the model: midlatitude/emissions parameters ("ML"), removal/transformation parameters ("RT"), or local Arctic parameters ("ARC"). In each of the 10 sensitivity simulations, only one process is effectively modified at a time. By grouping the sensitivity simulations into categories, we aim to assess the relative importance of difference mechanistic and spatial drivers on Arctic atmospheric PCB concentrations.

In the ML category, sensitivity simulations address the effect of (1) ocean emissions, (2) temperature dependency of primary emissions, and (3) re-emissions from all surfaces to the atmosphere. For (1), we increase ocean concentrations by $\sim 100 \times$. We do this by re-running the $1930-1978$ with the ocean depth decreased by a factor of 10 (from $1000 \mathrm{~m}$ to $100 \mathrm{~m}$ ). Additionally, we artificially increase ocean concentrations globally in 1979 by a factor of 10 . We categorize this as an ML sensitivity simulation because ocean concentrations are highest in the midlatitudes. To address (2), our sensitivity simulation removes the temperature dependency of the primary emissions rate (shown above in Eq. 1) such that $E_{T_{2}}=E_{T_{1}}$. For (3) we assume all deposited PCB 28 is re-emitted to the atmosphere by turning off all loss processes in surface media except for re-emissions, as a way to artificially increase secondary emissions to an upper-limit level.

In the RT category, our sensitivity simulations examine the effect of (1) dry deposition, (2) slower oxidation, (3) faster oxidation, and (4) temperature sensitivity. For (1) 
we turn off dry deposition and for (2) we turn off oxidation processes in the model to assess upper-limit (i.e., extreme and not necessarily realistic) manipulations on the main loss/transformation routes of CB 28. For (3), there is substantial uncertainty associated with measured PCB OH reaction rate constants (Anderson and Hites, 1996), and we test the impact of that uncertainty by replacing the average measured $k_{\mathrm{OH}}$ value $\left(1.1 \times 10^{-12} \mathrm{~cm}^{3} \mathrm{~s}^{-1}\right)$ with the upper $95 \%$ confidence limit value $\left(1.4 \times 10^{-12} \mathrm{~cm}^{3} \mathrm{~s}^{-1}\right)$. This serves to test the opposite effect of turning off all oxidation (no. 2 above), but also in a more realistic way. For (4), to test whether Arctic dynamics of CB 28 depend on its sensitivity to temperature changes, we replace $\Delta H$ for CB 28 with that of $\mathrm{CB}$ 153 , which has a larger absolute value $\left(94.8 \mathrm{~kJ} \mathrm{~mol}^{-1}\right.$ versus $78.4 \mathrm{~kJ} \mathrm{~mol}^{-1}$; both values from Schenker et al., 2005) and will thus induce stronger changes in both primary and secondary emissions rates depending on temperature changes (e.g., Lamon et al., 2009).

In the ARC category, we assess (1) the influence of Arctic (both primary and secondary) emissions, (2) scavenging by snow, and (3) re-emissions from snow. For (1), we turn off all (primary and secondary) Arctic emissions to quantify the contribution of local emissions to Arctic CB 28 concentrations. For (2), we turn off snow scavenging of PCBs in the atmosphere to assess whether scavenging by snow, which is more prevalent at the high latitudes than midlatitudes, has a substantial effect on Arctic concentrations and seasonal cycles. For (3), we increase snow re-emissions by increasing the wind pumping factor in the snowpack by $100 \times$. Previous studies have shown that when wind blows across the snowpack surface, interstitial air in the snow is ventilated and POP exchange between the snow and the atmosphere is enhanced. For example, Hansen et al. (2006) demonstrated that modeled snow concentrations decreased by as much as $185 \%$ for CB 28 when wind pumping was included in the model.

We note that while several of our sensitivity simulations address the impact of temperature on both primary and secondary emissions (e.g., ML2), as well as gas-particle partitioning (e.g., RT4), degradation of PCBs is impacted by temperature changes as well (via the Arrhenius equation). We did not explicitly test the impact of changes in degradation parameters in this study.

\section{Results}

We first present a global evaluation of the model for each of the ICES congeners by comparing annual means of simulated and measured concentrations at specific measurement sites. We look in closer detail at CBs 28 and 153, two congeners that span a range of volatilities, by comparing simulated results to a 1991-2010 measured time series. We then present global budgets and lifetimes for all congeners and, finally, assess the results of sensitivity simulations to quantify the relative effects of parameters associated with ML, RT, and
ARC spatial/transport drivers on CB 28 concentrations in the Arctic.

\subsection{Model evaluation}

\subsubsection{Annual mean concentrations}

Figure 1 shows global simulated annual mean concentrations from 2006 to 2010 (background) compared to observations (circles). Observations come from non-urban long-term measurement sites using high-volume air samplers, listed in Table 1. Table 2 compares the same data when averaged spatially. We present the results for the NH (Arctic and nonurban midlatitude (NUML) sites) and an Antarctic site separately. Simulated concentrations in the Arctic range from $24 \%$ (CB 180) to 1.3 times (CB 118) observed Arctic concentrations, while NUML simulated concentrations are between $34 \%$ (CB 101) and 1.6 times (CB 28) observed. Simulated-to-measured ratios for CB 28 and CB 118 are greater than 1 for all locations while for all other congeners the ratio is consistently less than 1 , though there is substantial uncertainty in these values given that they are spatial and temporal averages. Also shown in Table 2 are observed and simulated ratios of NUML to Arctic concentrations. Both sets of ratios generally increase with increasing $\log K_{\mathrm{OA}}$, though the relationship is not statistically significant at $\alpha=0.05$ ( $p=0.14$ and 0.08 for observations and model results, respectively). The increase, however, indicates greater long-range transport potential for congeners that do not deposit as readily (as deposition increases with increasing $\log K_{\mathrm{OA}}$ in the model). This is consistent with the "differential removal" hypothesis from von Waldow et al. (2010). In the Antarctic, simulated concentrations range from $25 \%$ (CB 180) to 1.4 times (CB 28) observed concentrations, demonstrating that the model captures the approximately order of magnitude difference observed between the Arctic and Antarctic for all congeners.

Table 3 provides linear relationships and correlations between simulated and observed mean annual concentrations for all NH non-urban locations (i.e., NUML + Arctic sites). Pearson correlation coefficients, which provide a measure of how well the model is able to reproduce variability in the measurements, range from 0.53 (CB 118) to 0.75 (CBs 180). There was no systematic bias in the model with congener volatility. Slopes and intercepts of linear best fit equations range from 0.17 to 1.15 and 0.07 to 1.28 , respectively, indicating measured and modeled data are well within an order of magnitude of one another.

\subsubsection{Monthly and seasonal mean concentrations from 1991 to 2010 (CBs 28 and 153)}

GEOS-Chem compares favorably to previous PCB models using the same emissions inventory (e.g., GEM-POPs and BETR-Global from Huang et al., 2007, and Lamon et al., 
Table 1. Stations where observational data were obtained; first four sites are considered Arctic. References: (a) Hayley Hung/Northern Contaminants Program, personal communication; (b) EMEP (Cooperative Programme for Monitoring and Evaluation of the Long-range Transmissions of Air Pollutants in Europe); (c) Helena Dryfout-Clark/IADN (Integrated Atmospheric Deposition Network), Environment Canada, personal communication. ${ }^{1}$ Site considered urban and not included in model-measurement comparison. ${ }^{2}$ Site where total deposition is measured. Sites listed in bold/italics were averaged as they occurred within the same model grid box.

\begin{tabular}{rrrlc}
\hline Latitude & Longitude & Elevation (m) & Station name & Reference \\
\hline 82 & -62 & 30 & Alert, Canada & $\mathrm{a}$ \\
78.9 & 11.9 & 474 & Zeppelin, Norway & $\mathrm{b}$ \\
69.3 & 16 & 380 & Andoya, Norway & $\mathrm{b}$ \\
68 & 24.2 & 340 & Pallas (Matorova), Finland & $\mathrm{b}$ \\
64.1 & 21.9 & 52 & Reykjavik, Iceland & $\mathrm{b}$ \\
58.8 & 17.38 & 20 & Aspvreten, Sweden & $\mathrm{b}$ \\
58.4 & 8.3 & 190 & Birkenes, Norway & $\mathrm{b}$ \\
58.4 & 8.3 & 219 & Birkenes II, Norway & $\mathrm{b}$ \\
57.4 & 11.9 & 5 & Rao, Sweden & $\mathrm{b}$ \\
54.9 & 8.3 & 12 & Westerland, Germany & $\mathrm{b}$ \\
54.4 & 12.7 & 1 & Zingst, Germany & $\mathrm{b}$ \\
54.3 & -0.8 & 267 & High Muffles, Great Britain & $\mathrm{b}$ \\
53 & 70.6 & 334 & Borovoe, Kazakhstan & $\mathrm{b}$ \\
50.7 & 10.8 & 937 & Schmucke, Germany & $\mathrm{b}$ \\
49.6 & 15.1 & 534 & Košetice, Czech Republic & $\mathrm{b}$ \\
47.9 & 7.9 & 1205 & Schauinsland, Germany & $\mathrm{b}$ \\
$\mathbf{4 7 . 5}$ & $-\mathbf{8 8 . 1}$ & $\mathbf{1 8 5}$ & Eagle Harbor, USA & $\mathrm{c}$ \\
46.5 & 28.3 & 166 & Leova II, Moldova & $\mathrm{b}$ \\
$\mathbf{4 5 . 8}$ & $-\mathbf{8 9 . 2}$ & $\mathbf{1 8 4}$ & Burnt Island, Canada & $\mathrm{c}$ \\
44.8 & -86.1 & 241 & Sleeping Bear Dunes, USA & $\mathrm{c}$ \\
43.8 & -77.2 & 78 & Point Petre, Canada & $\mathrm{c}$ \\
42.7 & -79.1 & 176 & Sturgeon Point, USA & $\mathrm{c}$ \\
41.8 & -87.6 & 199 & Chicago, USA & $\mathrm{c}$ \\
41.5 & -81.7 & 204 & Cleveland, USA & $\mathrm{c}$ \\
-72 & 2.5 & 1309 & Troll, Antarctica & $\mathrm{b}$ \\
\hline & & &
\end{tabular}

2009). For CBs 28 and 153, we find that the model predicts observed seasonal concentrations within a factor of $10^{0.5}$ $77 \%$ of the time and within a factor of $1098 \%$ of the time (Fig. 2). For comparison, the BETR-Global model predicted CB 28 and 153 observed concentrations within a factor of $10^{0.5} 64 \%$ of time and within a factor of $1096 \%$ of the time (Lamon et al., 2009). This gives us confidence that GEOSChem has the ability to simulate site-specific changes in atmospheric concentrations.

The model captures episodic events and seasonal cycles well in the midlatitudes but has less skill in the Arctic. Figures 3 and 4 present monthly time series and long-term monthly averages of CBs 28 and 153, respectively, at Zeppelin (Norway) and Burnt Island (Canada).

For both CB 28 and 153, the model reproduces the Burnt Island monthly time series in terms of mean concentrations (simulated concentrations are 1.6 and 1.3 times higher for CBs 28 and 153, respectively) and captures the observed seasonal cycle with a peak in concentrations in summer months and a trough in the winter. This seasonal cycle is observed at all midlatitude stations. The model also reproduces the slow decline in concentrations observed in the measure- ments, though in the case of CB 28 at a slightly faster rate; this rate is primarily dictated by the rate of decline in primary emissions. The Pearson correlation coefficient $(r)$ values for the monthly concentrations averaged over time are 0.97 (CB 28) and 0.99 (CB 153) at Burnt Island, and the overall trend agreement between the model and measurements at this NUML station can be seen in the upper right quadrants of Figs. 3 and 4.

The model has less skill at capturing the observed Arctic (Zeppelin) seasonal cycle, particularly for CB 28. Though absolute simulated concentrations are close to measured on average (simulated concentrations are 0.55 and 0.59 times observed concentrations of CB 28 and 153, respectively), the observed cycle of CB 28 is similar to that in the midlatitudes, with a summer maximum and a winter minimum, while the model simulates the opposite pattern (summer minimum, winter maximum). Thus, there is a strong anticorrelation between observed and simulated concentrations $(r=-0.75$ for the monthly concentrations averaged over time). For CB 153, there is an observed general seasonal cycle with two maxima in the observations. Though not consistent, there is usually a peak in the late spring through late summer and another in the 

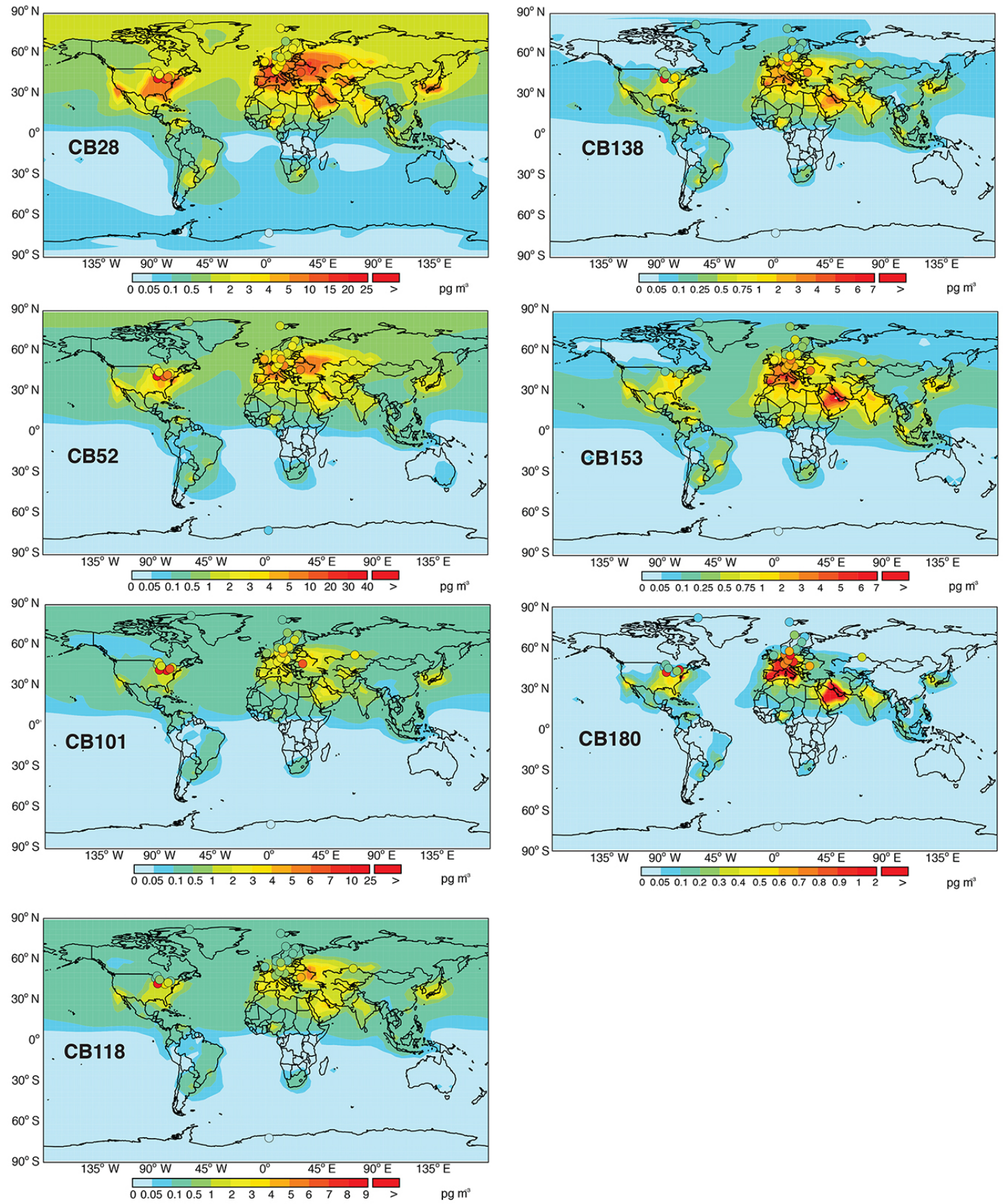

Figure 1. Average total (gas + particulate) simulated PCB concentrations in surface air from 2006 to 2010 (background) and land-based observations (circles) from measurement stations listed in Table 1. Observations are interannual means from 2006 to 2010 , except in some cases where only a subset of data was available.

late fall or early winter. This is true for the simulated concentrations as well, with the larger peak arriving in June-August and a smaller peak in November-January. However, because the model predicts maxima roughly a month before observed maxima, the correlation is not very strong ( $r=0.25$ for the monthly concentrations averaged over time). This mismatch is explored further in our sensitivity simulation with CB 28 .

\subsection{Global atmospheric budgets and lifetimes}

The budget from simulated years 2006-2010 indicates that for all congeners the atmosphere, vegetation, lakes, and snow are at steady state, while the ocean and soils are emitting legacy deposition. Table 4 summarizes the atmospheric portion of the budget. Dry deposition of the gas phase and $\mathrm{OH}$ 


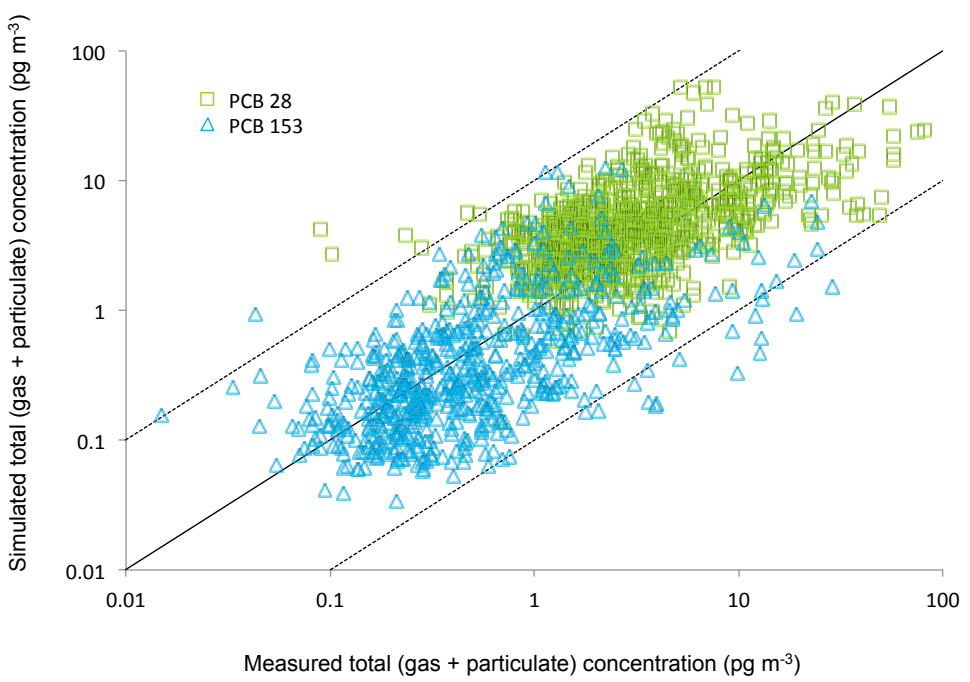

Figure 2. Comparison of seasonal averages of simulated and measured total concentrations of CBs 28 and 153 . Measurement data come from 23 different non-urban monitoring sites in the Northern Hemisphere, which correspond to 21 different GEOS-Chem grid boxes. The solid line represents a $1: 1$ relationship, while the dashed lines represent the boundaries where simulated concentrations are 0.1 and 10 times measured concentrations.

oxidation are the two main loss routes for all seven congeners, though their relative importance changes across the congener spectrum. For example, dry deposition accounts for $82 \%$ of the loss of CB 180 but only $30 \%$ for CB 28 . Conversely, $\mathrm{OH}$ oxidation accounts for $65 \%$ of the loss of CB 28 but only $13 \%$ for CB 180 . Though we predict substantially lower total masses of PCBs in the atmosphere compared to other PCB modeling studies (e.g., Huang et al., 2007, whose simulated concentrations generally biased high while ours generally bias low), the relative percentages of loss due to oxidation versus deposition across congeners are similar. Wet deposition plays a relatively minor role in the global budget; wet deposition accounts for only $4 \%$ (CB 138) to $7 \%$ (CB 180 ) of total losses and only $5 \%$ (CB 138) to $14 \%$ (CB 28) of total deposition. More than $99 \%$ of wet deposition, for all congeners, is of the gas phase. This is true for the Arctic in particular as well.

The particle phase makes up only a very small fraction of the total budget for all congeners. CB 28 has the least in the particle phase $(0.02 \%)$ while CB 180 has the most $(1.4 \%)$. While these fractions are low compared to measured PCB particulate fractions, especially for the heavier congeners like CB 180, most measurements of particulate fractions are in urban areas (e.g., Simcik et al., 1998); the fractions we report here are global averages and are thus lower than particulate fractions found near urban locations. The low PCB particulate fractions are in contrast to GEOS-Chem simulations of PAHs, where $93 \%$ of benzo[a]pyrene was found to be in the particle phase (Friedman and Selin, 2012). The difference can be attributed to PAH preferentially strongly binding to $\mathrm{BC}$, a process that has not been observed to the same degree for PCBs and hence does not exist in the PCB model (BC and OC particles are treated as one particle type for PCBs, with partitioning controlled by the $K_{\mathrm{OA}}$ for both). The small fraction in the particle phase results in nearly all wet and dry deposition (>99\% for all congeners) being attributable to the gas phase.

The relative contribution of re-emissions to total atmospheric emissions generally decreases with increasing degree of chlorination. CB 52 has the highest percentage of reemissions (9.2\%), while CB 180 has the least (1.9\%). Reemissions can enhance transport to remote regions, as they can occur anywhere PCBs have previously deposited; this is consistent with the different distributions seen in the Arctic across congeners in Fig. 1 (i.e., a greater fraction of CB 28 in the Arctic atmosphere versus CB 180) and the increase in measured NUML-to-Arctic ratios with increasing chlorination shown in Table 2 , which is generally captured by the model.

The model predicts short atmospheric lifetimes of PCBs, ranging from 4.5 to $9.4 \mathrm{~h}$ (for CBs 180 and 28, respectively). We note that, in contrast to effective lifetimes often quoted in previous literature, these atmospheric residence times only take into account gross losses and do not consider re-emissions or storage in surface reservoirs.

We do not focus on surface media budgets here other than to note that for all surface media except snow, re-emissions generally do not contribute substantially to losses from the surface. Degradation and deposition to sediments (for oceans and lakes) usually account for the largest losses. In the case of snow, re-emissions account for $22 \%$ (CB 180) to $56 \%$ (CB 52) of losses. 


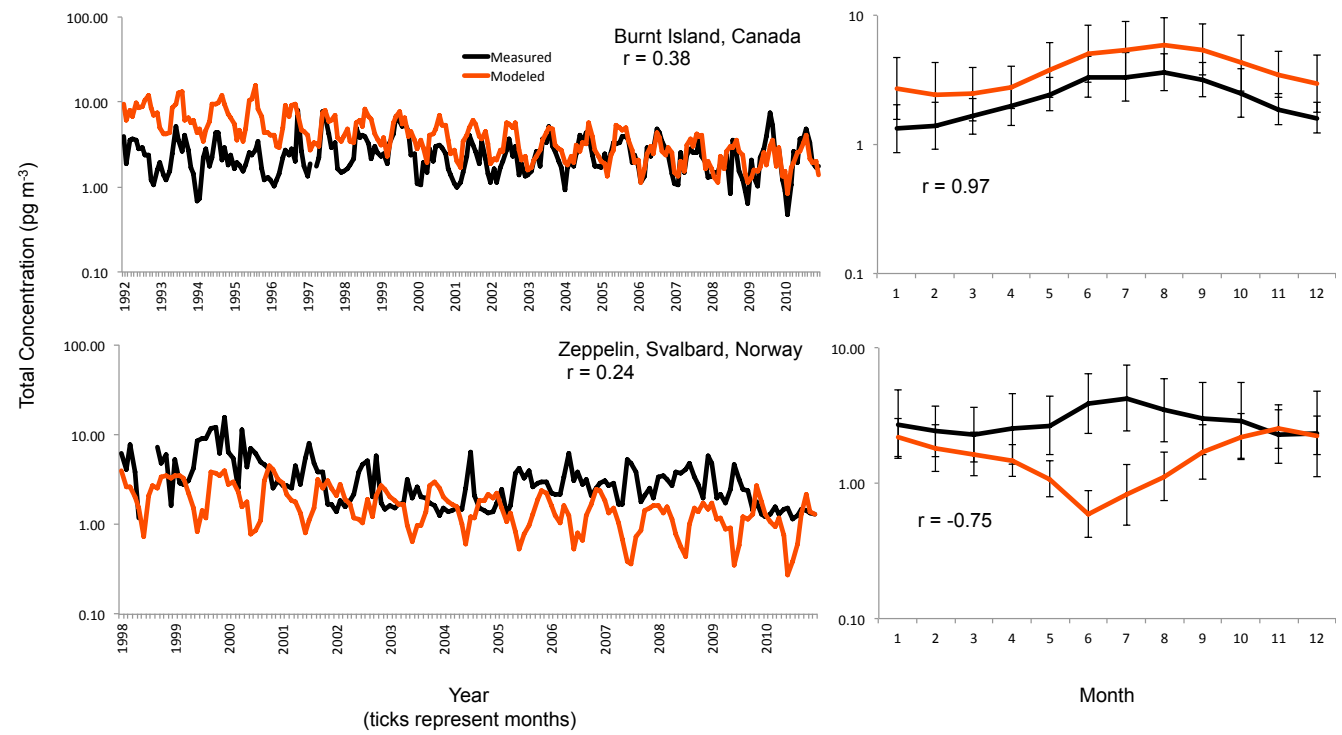

Figure 3. Total measured and simulated monthly mean concentrations of CB 28 at Burnt Island, Canada (top row), and Zeppelin, Norway (bottom row). The left-hand column is the full time series, while the right-hand column is an average of the data on the left over all years.

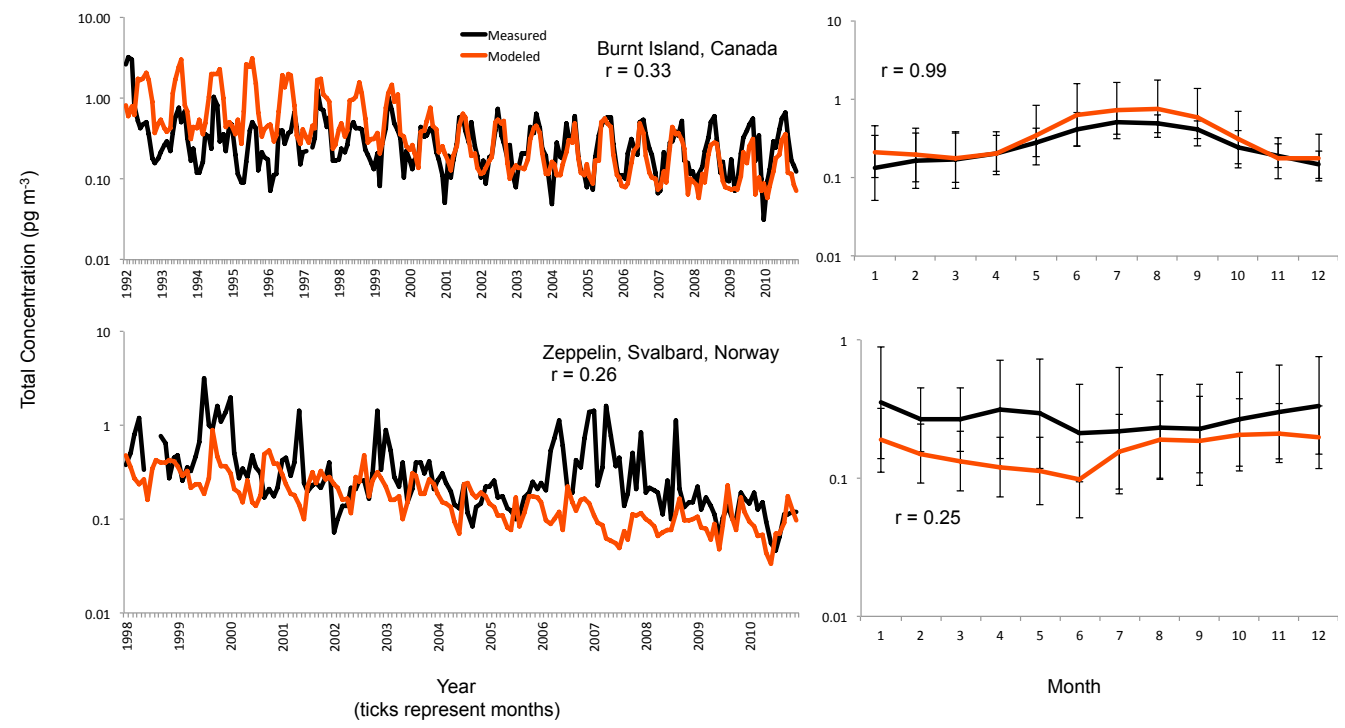

Figure 4. Total measured and simulated monthly mean concentrations of CB 153 at Burnt Island, Canada (top row), and Zeppelin, Norway (bottom row). The left-hand column is the full time series, while the right-hand column is an average of the data on the left over all years.

\subsection{Sensitivity of Arctic concentrations to different spatial drivers}

We focus our Arctic sensitivity analyses on CB 28 because (a) its removal from the atmosphere is not dominated by one loss pathway - i.e., it is sensitive to changes in both dry deposition and oxidation - and (b) it is one of the more volatile congeners of the ICES suite, so re-emissions of previously deposited chemical play a larger role in its LRT. This is important because re-emissions have been identified as important in a number of studies attempting to identify the source of recent observed increases in Arctic atmospheric PCBs (Ma et al., 2011; Zhao et al., 2015). In this section, all comparisons are for changes in surface atmospheric concentrations averaged over the entire Arctic $\left(66-90^{\circ} \mathrm{N}, 180^{\circ} \mathrm{W}-180^{\circ} \mathrm{E}\right)$.

Our sensitivity analyses are divided into three different "Arctic driver" categories, depending on what was altered in the model: midlatitude/emissions parameters ("ML"), removal/transformation parameters ("RT"), or local Arctic parameters ("ARC"). Table 5 shows the results of the changes from each category on both absolute concentrations as well as the seasonal variation, averaged over simulated time 


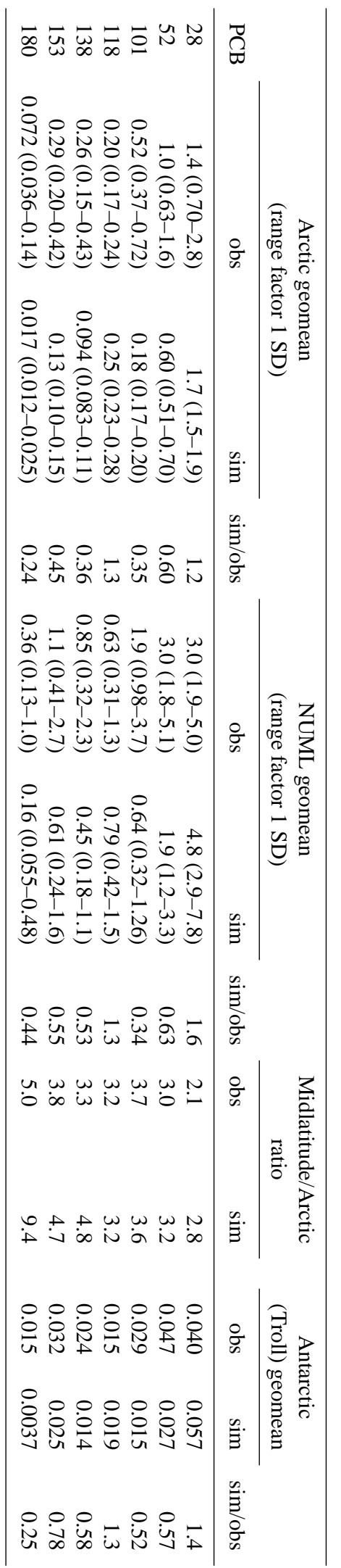

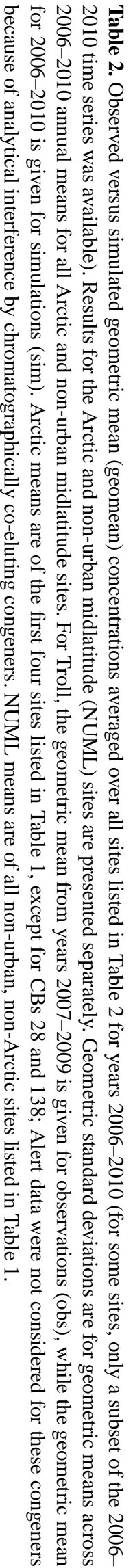

Table 3. Linear relationships and correlations between simulated and observed mean annual (2006-2010) concentrations for all NH non-urban locations (i.e., NUML + Arctic sites) with Pearson correlation coefficient $(r)$ values, mean bias, and root mean square error $\left(\mathrm{pg} \mathrm{m}^{-3}\right)$.

\begin{tabular}{rlrrr}
\hline PCB & Linear relationship & $r$ & Bias & RMSE \\
\hline 28 & $Y=1.15 x+1.28$ & 0.64 & 1.73 & 2.69 \\
52 & $Y=0.32 x+0.95$ & 0.57 & -1.12 & 2.05 \\
101 & $Y=0.17 x+0.32$ & 0.56 & -1.41 & 1.91 \\
118 & $Y=0.46 x+0.48$ & 0.53 & 0.12 & 0.54 \\
138 & $Y=0.25 x+0.25$ & 0.61 & -0.57 & 1.00 \\
153 & $Y=0.40 x+0.19$ & 0.73 & -0.53 & 0.90 \\
180 & $Y=0.27 x+0.07$ & 0.75 & -0.27 & 0.47 \\
\hline
\end{tabular}

(1992-2009). As noted above, there is a mismatch between measured and simulated seasonal variation. Sensitivity simulations that simultaneously increase absolute concentrations and decrease modeled seasonal cycle amplitude bring the model closer to observations, indicating that associated process changes may be more influential in the Arctic than changes in mean Arctic concentrations alone. Figure 5 shows the impact on seasonal cycle for simulations resulting in changes of at least $10 \%$. Concentrations in Fig. 5 have been normalized to a running mean so that the change in seasonal cycle can be viewed without interference from longterm changes in concentrations.

In the ML category, removing the temperature dependency of primary emissions (simulation ML2) has a greater effect on Arctic surface concentrations than increasing surface reemissions to the atmosphere (simulations ML1 and ML3). Removing the temperature dependency causes a $340 \%$ increase in mean Arctic surface concentrations compared to default simulations, while simultaneously increasing the seasonal cycle bias in the simulations (i.e., the wintertime high in the simulation is amplified). Thus, removing a key temperature-sensitivity parameter in the model increases the mismatch between observed and simulated Arctic PCB seasonal cycles and concentration magnitude. Extreme increases in re-emissions from all surfaces (simulation ML3) also has a relatively large effect on both mean concentrations and the seasonal cycle, with Arctic concentrations increasing by $260 \%$ and seasonal cycle amplitude decreasing by $34 \%$. Increasing ocean emissions alone, in a more realistic parameterization (simulation ML1), has a nearly negligible effect.

In the RT category, turning off dry deposition (RT1) and oxidation (RT2) demonstrates that these processes strongly influence mean Arctic concentrations. RT1 and RT2 result in 200 and $370 \%$ increases in mean Arctic concentrations and 11 and $27 \%$ decreases in the strength of the seasonal cycle, respectively. Conversely, increasing the oxidation rate (RT3) results in a decrease in concentrations $(-13 \%)$ and an increase in the strength of the simulated seasonal cycle $(8 \%)$. Altering the temperature sensitivity of emissions for CB28 
Table 4. Mean 2006-2010 atmospheric budget of PCBs. For all congeners, total wet and dry deposition was dominated by the gas phase (>99\% attributable to the gas phase).

\begin{tabular}{lrrrrrrr}
\hline & \multicolumn{7}{c}{ Congener } \\
\cline { 2 - 8 } Quantity associated with atmospheric budget & 28 & 52 & 101 & 118 & 138 & 153 & 180 \\
\hline Mass in atmosphere (kg) & 58 & 26 & 12 & 16 & 10 & 15 & 3.4 \\
Mean fraction in particle phase (\%) & 0.021 & 0.052 & 0.17 & 0.18 & 0.57 & 0.40 & 1.4 \\
OH oxidation losses (\%) & 65 & 53 & 35 & 34 & 21 & 25 & 13 \\
Dry deposition losses (\%) & 30 & 42 & 60 & 61 & 75 & 70 & 82 \\
Wet deposition losses (\%) & 5.1 & 4.6 & 4.9 & 4.9 & 4.0 & 5.2 & 5.8 \\
Re-emissions out of total emissions (\%) & 6.0 & 9.2 & 5.1 & 4.8 & 2.7 & 4.1 & 2.0 \\
Mean atmospheric lifetime (gas + particulate; h) & 9.4 & 8.1 & 6.7 & 6.5 & 5.3 & 5.9 & 4.5 \\
\hline
\end{tabular}

Table 5. Results of sensitivity simulations on mean surface atmospheric CB 28 Arctic concentrations. ${ }^{*}$ Measured by taking the ratio of mean January normalized concentrations. Simulations that increase the mean concentration while simultaneously decreasing the seasonal pattern amplitude (simulations ML3, RT1, and RT2) are those that bring model and observational results closer together.

\begin{tabular}{|c|c|c|c|c|c|}
\hline Arctic driver & $\begin{array}{l}\text { Simulation } \\
\text { name }\end{array}$ & $\begin{array}{l}\text { Simulation tests } \\
\text { sensitivity to }\end{array}$ & $\begin{array}{l}\text { Actual change to } \\
\text { simulation }\end{array}$ & $\begin{array}{l}\text { Effect on mean } \\
\text { concentration }\end{array}$ & $\begin{array}{l}\text { Effect on seasonal } \\
\text { pattern amplitude* }\end{array}$ \\
\hline \multirow[t]{3}{*}{$\begin{array}{l}\text { ML/Emissions } \\
\text { "ML" }\end{array}$} & ML1 & Ocean re-emissions & $\begin{array}{l}\text { Ocean concentrations } \\
\text { increased } \sim 100 \times\end{array}$ & $+2 \%$ & $+1 \%$ \\
\hline & ML2 & Temperature & $\begin{array}{l}\text { Emissions dependency on } \\
\text { temperature removed }\end{array}$ & $+340 \%$ & $+230 \%$ \\
\hline & ML3 & $\begin{array}{l}\text { All surface } \\
\text { re-emissions }\end{array}$ & $\begin{array}{l}\text { All losses from surface } \\
\text { media turned off except } \\
\text { re-emissions }\end{array}$ & $+260 \%$ & $-34 \%$ \\
\hline Removal/Transformation & RT1 & Reduced deposition & $\begin{array}{l}\text { All dry deposition turned } \\
\text { off }\end{array}$ & $+200 \%$ & $-11 \%$ \\
\hline \multicolumn{6}{|l|}{ "RT" } \\
\hline & RT2 & Reduced oxidation & All oxidation turned off & $+370 \%$ & $-27 \%$ \\
\hline & RT3 & Increased oxidation & $\begin{array}{l}\text { OH reaction rate constant } \\
\text { increased }\end{array}$ & $-13 \%$ & $+8 \%$ \\
\hline & RT4 & Temperature & Substitute $\Delta H$ of 153 & $-6 \%$ & $-12 \%$ \\
\hline \multirow[t]{3}{*}{$\begin{array}{l}\text { Arctic } \\
\text { "ARC", }\end{array}$} & ARC1 & Arctic emissions & $\begin{array}{l}\text { All Arctic emissions } \\
\text { turned off }\end{array}$ & $-5 \%$ & $+4 \%$ \\
\hline & ARC2 & $\begin{array}{l}\text { Reduced snow } \\
\text { scavenging }\end{array}$ & $\begin{array}{l}\text { Snow scavenging turned } \\
\text { off }\end{array}$ & $+7 \%$ & $+5 \%$ \\
\hline & ARC3 & $\begin{array}{l}\text { Increased snow } \\
\text { re-emissions }\end{array}$ & $\begin{array}{l}\text { Increase wind pumping } \\
\text { factor } 100 \times\end{array}$ & $+3 \%$ & No change \\
\hline
\end{tabular}

(RT4) resulted in a small decrease in mean concentrations $(-6 \%)$ and a decrease in seasonal cycle strength $(-12 \%)$

In the ARC category, turning off all local emissions causes a small decrease $(-5 \%)$ in mean concentrations and a small increase $(+4 \%)$ in seasonal cycle strength, demonstrating that their presence in the model is important to model-observation agreement. Removing snow scavenging from the atmosphere (simulation ARC2) causes minor increases in mean concentration and seasonal cycle strength ( +7 and $+5 \%$, respectively). Finally, increasing snow emissions (ARC3) causes a small increase in the mean Arctic concentration but no change in the seasonal cycle.
Overall, sensitivity simulations only reduce or increase the amplitude of the simulated CB 28 seasonal maxima but do not affect timing (Fig. 5), with the exception of Simulation ML2, which results in a slight shift in the timing of maxima (maxima occur approximately 1 month later).

We find that mean surface Arctic concentrations of CB 28 are positively correlated to the mean fraction of ice/snow in Arctic grid boxes $(r=0.46)$ and inversely correlated to both Arctic surface air temperatures $(r=-0.59)$ and midlatitude surface temperatures $(r=-0.56)$. 


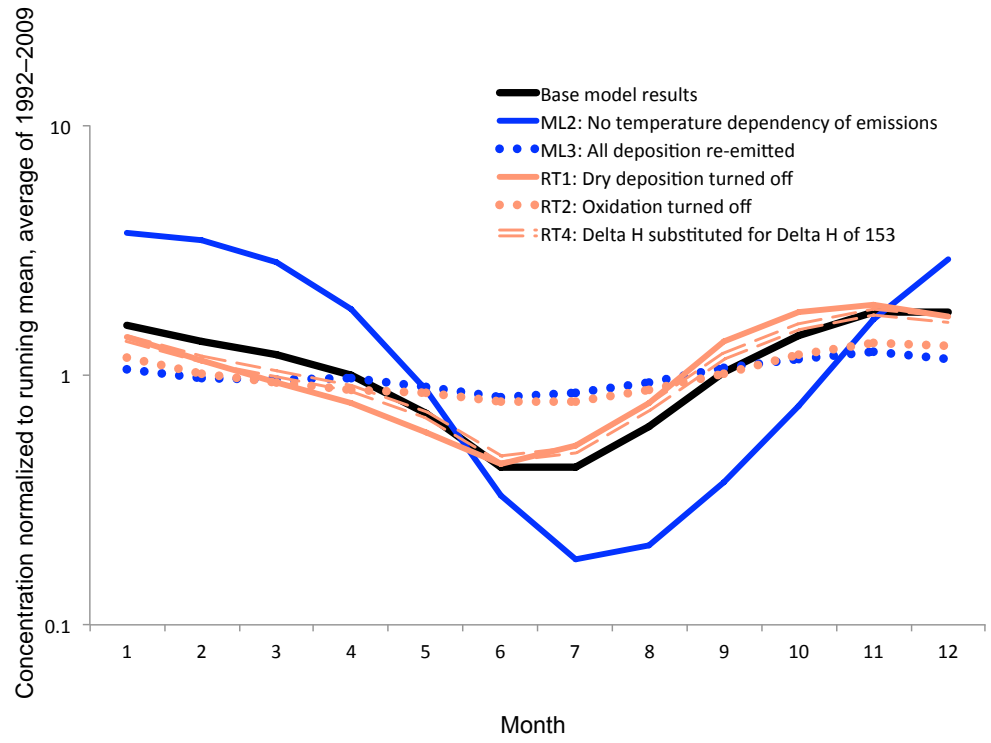

Figure 5. Changes in mean surface Arctic PCB 28 seasonal variation with sensitivity simulations, averaged over time (1992-2009). Simulated concentrations have been normalized to a running mean. Sensitivity simulations that flatten the simulated seasonal cycle are those that minimize the model-measurement gap in the Arctic.

\section{Discussion}

The model reproduces absolute concentrations of PCBs globally across congeners and simulates observed midlatitude seasonal cycles with accuracy. However, the simulation predicts opposite seasonal cycles (high in winter, low in summer) compared to observations at Arctic stations for the more volatile PCBs. This is somewhat consistent with a modeling study by Octaviani et al. (2005) who showed that the highest flux of PCBs into the Norwegian Arctic occurs during the fall season (September-October-November) and the minimum occurs during the summer (June-July-August). The opposition in observed and simulated seasonal cycles indicates that the model is missing an important process influencing the Arctic. We use our ML, RT, and ARC sensitivity simulations of CB 28 and their effect on simulated mean Arctic concentrations and seasonal cycles to assess the mismatch. We then discuss what our sensitivity simulations imply about the influence of relevant processes controlling PCB concentrations in a changing climate.

The direction of change induced by sensitivity simulations (Table 5) can be used in conjunction with the modelmeasurement mismatch to assess potential drivers of Arctic PCBs and indicate what processes the model is missing that might account for the summer high seen in observations. Sensitivity simulations that simultaneously increase the mean Arctic concentration and reduce the strength of the simulated seasonal cycle are those that bring modeled and measured concentrations and temporal patterns closer together. Thus, our sensitivity simulations suggest that less dry deposition, less oxidation, and higher re-emissions in the model would help close the model-measurement gap in the Arctic (i.e., simulations RT1, RT2, and ML3).

Supporting evidence beyond sensitivity simulations exists to indicate the model assumes oxidation and deposition rates that are too fast. In the case of oxidation, there are few measurements of $\mathrm{PCB} \mathrm{OH}$ reaction rate constants. Most modeling studies rely on one set of measurements obtained decades ago (Anderson and Hites, 1996). A number of studies examining atmospheric PCB measurements and constructing global budgets have suggested that the rates measured by Anderson and Hites are too high to account for observed spatial distributions across congeners (e.g., Axelman and Gustafsson, 2002). Also, model particulate fraction results are biased low for the higher molecular weight congeners compared to measurements; a greater fraction of PCB in the particulate phase may reduce the overall mass lost from oxidation. Similarly, while there are only three stations from Table 1 routinely measuring total deposition, a comparison between model results and measurements demonstrates that CB 28 deposition (which is dominated by dry deposition of the gas phase) is approximately an order of magnitude too high in the model (data not shown). Thus, reducing oxidation and dry deposition rates are reasonable changes to make to the model, though we note that these changes also increase concentrations in the midlatitudes where the model is already skilled at predicting concentrations.

Simulation ML3, in which re-emissions are increased to an extreme upper limit, shows that increasing secondary emissions in the model also helps close the model-measurement gap in the Arctic. However, other sensitivity simulations that also increase secondary emissions in the Arctic, but in a more 
realistic/less extreme manner, such as increased ocean and snow re-emissions (ML1 and ARC3, respectively), lead only to minor increases in atmospheric concentrations and have virtually no effect on the seasonal pattern. This suggests that secondary emissions would have to be unrealistically high in order to match Arctic observations without affecting the model-measurement match in the midlatitudes.

In the absence of secondary emissions as a likely source of model-measurement mismatch, local primary emissions that are not accounted for in the Breivik emissions inventory deserve attention. While Arctic monitoring stations are situated such that the impact of local contamination should be minimal, contamination issues have been observed in remote locations where measurement platforms rely on older building materials that potentially contain PCBs. For example, the continuous diffusive emissions of PCBs from older ships during remote ocean measurements has been documented (Lohmann et al., 2004), while hot spots of PCBs and other POPs have been observed near Antarctic research stations (Cabrerizo et al., 2012; Kennicutt II et al., 1995; Wild et al., 2015). The Alert station is located near a Canadian military station with buildings from at least the 1950s, while the Zeppelin station is just south of Ny-Ålesund, a research settlement formed in the 1960s but which has hosted mining operations since the early 1900s. Given the greater effect of temperature changes on primary volatilization emissions compared to secondary emissions found both here and in other modeling studies (Lamon et al., 2009), it seems plausible that the maxima seen in the remote Arctic summer could be attributed to unaccounted-for local primary emissions. We also note that while observed atmospheric concentrations of POPs have been shown to be positively correlated to both sea ice retreat and surface temperature in the Arctic (Ma et al., 2011), the multicollinearity of sea ice retreat and surface temperature was not discussed; i.e., it is possible that the observed seasonal cycle is driven primarily by temperature alone. Thus, based on our model results and supporting data, we consider local primary emissions a more probable driver of summer concentration maxima compared to re-emissions from surface media.

Except for the possibility of unaccounted-for local primary emissions, even when the more probable missing model processes are considered, simulated Arctic PCB concentrations are mostly controlled by factors outside of the region. We hypothesize based on this result that the main factors driving observed variability in Arctic PCB concentrations result from processes outside the Arctic. The sensitivity simulations that minimize the model-measurement gap in the Arctic (ML3, RT1, and RT2) are those that alter processes that mainly take place outside the Arctic. Also, the ML and RT categories of sensitivity simulations generally cause a much larger percent change in mean concentrations and seasonal cycle compared to ARC sensitivity simulations. Much of the greater magnitude of change from the ML and RT scenarios is attributable to the fact that changes within these categories affect nearly all emitted PCBs globally, while ARC simulation changes affect primarily only PCBs emitted or deposited in the Arctic. This points to the importance of accurate quantification and spatial attribution of emissions globally for assessing changes in Arctic PCB levels.

If absent Arctic primary emissions are indeed the main cause of model-measurement mismatch, then our conclusion above that factors outside the region control PCB concentrations would need revising. With the model in its current form, simulated Arctic concentrations have a weak inverse correlation with midlatitude temperatures. This suggests that the simulated seasonal pattern mostly reflects strong wintertime transport rather than temporal variation in midlatitude emissions and thus that the simulated Arctic is mostly influenced by physical transport. The polar front, which moves toward the poles in the summer and toward the midlatitudes in the winter, has been implicated as a factor in deviations in PCB concentrations measured at distinct Arctic stations (Kallenborn et al., 2007); however, it does not appear to play a large role in simulated average Arctic PCB concentrations. Primary emissions are sensitive to changes in temperature, and it is likely that with additional Arctic primary sources beyond those accounted for in the Breivik inventory, summertime temperature increases would cause an increase in atmospheric concentrations that would dominate a long-range transport signal. As discussed above, we do not consider secondary emissions in the Arctic to be a probable cause of seasonal cycle mismatch because of the extreme increase required in the model in order to match observations. Additional evidence for secondary emissions as an unlikely cause of seasonal cycle is the positive correlation in our simulations between concentrations and ice/snow cover in the Arctic, which suggests surface media associated with lower temperatures (e.g., snow/ice) leads to higher atmospheric concentrations than surface media associated with warmer temperatures (e.g., open ocean/soil). Indeed, previous modeling studies (Hansen et al., 2006; Stocker et al., 2007) have suggested that the presence of a surface snowpack increases atmospheric concentrations of volatile POPs compared to a surface without snow, because of the tendency for volatile POPs to be re-emitted quickly (Daly and Wania, 2004). This means that a summertime retreat in snow/ice is unlikely to be the source of higher concentrations in the Arctic.

Our results can be considered in the context of climate change and the current literature. Previous studies aimed at assessing the role of changing climate on Arctic PCB concentrations have suggested the break up of sea ice and exposure of the Arctic Ocean with warmer temperatures accounts for increases in Arctic atmospheric PCBs (Ma et al., 2011; Zhao et al., 2015). Most of the evidence presented by Ma et al., however, focuses on POPs that are more volatile than PCBs, such as $\alpha-\mathrm{HCH}$, and the concentration increases in PCBs cited at Arctic stations were more prominent for heavier congeners, which are less likely to volatilize. Both Ma et al. (2011) and Zhao et al. (2015) employed pertur- 
bation modeling, which assumes a closed system with simplifications of Arctic-specific processes and neglects transport from outside the region. In contrast, our results suggest that changes in long-range transport and/or volatilization of local primary sources would overwhelm release of legacy PCBs from sea ice or the Arctic Ocean. Changes in longrange transport due to climate change are likely to take the form of faster atmospheric degradation rates and increases in midlatitude primary emissions relative to the present climate (Hansen et al., 2015; Lamon et al., 2009; Wornschimmel et al., 2013), processes which change PCB concentrations in opposite directions and thus make it difficult to predict the effect on the Arctic. There is also literature that supports the idea that Arctic secondary emissions will not play a major role in atmospheric PCB levels there with a changing climate. Gioia et al. (2008) conducted PCB measurements over the Arctic Ocean and their results suggest the Arctic is under a strong net PCB deposition regime rather than net volatilization. Likewise, Sobek and Gustafsson (2014) recently constructed a budget of PCBs in the Arctic Ocean which suggests $98 \%$ of PCBs reside in the deep and intermediate waters, with surface water and ice containing insignificant masses in comparison. Combined with evidence of increasing primary productivity and carbon export to sediments with climate change, the authors concluded a significant flux of PCBs out of the Arctic Ocean with warmer temperatures is unlikely; rather, it was suggested that net uptake from the atmosphere will increase in importance with changing climate. This is consistent with a study by Armitage and Wania (2013), who found that increases in particulate organic carbon in the Arctic Ocean may be one of the most important factors in controlling the concentrations of Arctic POPs under future climate.

It should be noted that our model includes substantial uncertainties with regard to predicting secondary emissions, especially with respect to re-emissions from oceans and ice. The ocean in the GEOS-Chem model is an embedded box model and thus does not consider lateral transport, which can be a key factor in moving soluble POPs from the midlatitudes to more remote regions. It is possible that in an ocean model with resolved surface and subsurface layers, that also includes particle dynamics and lateral transport, we may see enhanced secondary emissions. Snow and ice are also combined as one substance in the model and treated as snow. Snow is more porous than ice and, because of this, snow cover has been shown to increase atmospheric concentrations for volatile POPs (Hansen et al., 2006; Stocker et al., 2007; Wornschimmel et al., 2013). Ice has greater potential than snow to trap POPs and release them in melt water with warmer temperatures, which has been shown in studies examining melting glaciers (Bogdal et al., 2010); however, the effect of melting ice on atmospheric PCB concentrations is not well studied. A more realistic parameterization of Arctic sea ice dynamics could also potentially increase simulated re-emissions in the Arctic; however, the increase would have to be substantial to invalidate our conclusions.

\section{Conclusion}

We constructed a spatially and temporally resolved global atmospheric PCB model, driven by meteorological data, that is skilled at simulating mean atmospheric PCB concentrations and seasonal cycles in the Northern Hemisphere midlatitudes and mean Arctic concentrations. The model does not capture observed Arctic summer time maxima. We use the model to estimate global budgets for the ICES 7 PCBs, and our simulations demonstrate that in accordance with the "differential removal" hypothesis (von Waldow et al., 2010), a greater fraction of emitted PCB is transported to remote regions (ie., the Arctic) for congeners that do not readily deposit compared to those that do. Using a number of sensitivity simulations, grouped into three categories depending on whether they affect processes within, outside, or transport to the Arctic, in conjunction with the model-measurement mismatch in the Arctic, we examined the influence of climate- and emissionsdriven processes on Arctic concentrations. Based on these simulations, we find evidence for the hypothesis that processes outside rather than within the Arctic primarily affect Arctic atmospheric PCB levels. Our simulations suggest that re-emissions from sea ice melting or from the Arctic Ocean during summer would have to be unrealistically high in order to capture observed Arctic concentrations. We conclude that while previous studies have suggested climate change will induce re-emissions from Arctic sea ice and the Arctic Ocean, there is little evidence in our results to expect significant fluxes out of Arctic surface media compared to changes from transport from the midlatitudes.

\section{The Supplement related to this article is available online at doi:10.5194/acp-16-3433-2016-supplement.}

Acknowledgements. We acknowledge support from the US National Science Foundation's Arctic Natural Sciences program no. 1203526, Dynamics of Coupled Natural Human Systems program no. 1313755, and Atmospheric Chemistry program no. 1053648. CLF was partially supported under NIH Training Grant T32-ES007-020. We thank Colin Thackray (MIT) and Helen Amos (Harvard University) for helpful discussions and computing assistance, and Hayley Hung (Environment Canada and Northern Contaminants Program) for helpful discussions regarding Alert PCB data interpretation.

Edited by: R. Ebinghaus 


\section{References}

Abraham, M. H. and Al-Hussaini, A. J. M.: Solvation parameters for the 209 PCBs: calculation of physicochemical properties, J. Environ. Monitor., 7, 295-301, 2005.

Accardi-Dey, A. and Gschwend, P. M.: Assessing the combined roles of natural organic matter and black carbon as sorbents in sediments, Environ. Sci. Technol., 36, 21-29, 2002.

Anderson, P. N. and Hites, R. A.: OH radical reactions: The major removal pathway for polychlorinated biphenyls from the atmosphere, Environ. Sci. Technol., 30, 1756-1763, 1996.

Armitage, J. M. and Wania, F.: Exploring the potential influence of climate change and particulate organic carbon scenarios on the fate of neutral organic contaminants in the Arctic environment, Environ. Sci Process. Impacts, 15, 2263-2272, 2013.

Arp, H. P. H., Schwarzenbach, R. P., and Goss, K.-U.: Ambient gas/particle partitioning. 2: The influence of particle source and temperature on sorption to dry terrestrial aerosols, Environ. Sci. Technol., 42, 5951-5957, 2008.

Axelman, J. and Gustafsson, O.: Global sinks of PCBs: A critical assessment of the vapor-phase hydroxy radical sink emphasizing field diagnostics and model assumptions, Global Biogeochem. Cy., 16, 1111, doi:10.1029/2002GB001904, 2002.

Bogdal, C., Nikolic, D., Lüthi, M., Schenker, U., Scheringer, M., and Hungerbühler, K.: Release of legacy pollutants from melting glaciers: model evidence and conceptual understanding, Environ. Sci. Technol., 44, 4063-4069, 2010.

Breivik, K., Sweetman, A., Pacyna, J. M., and Jones, K. C.: Towards a global historical emission inventory for selected PCB congeners - a mass balance approach 2. Emissions, Sci. Total Environ., 290, 199-224, 2002.

Breivik, K., Sweetman, A., Pacyna, J. M., and Jones, K. C.: Towards a global historical emission inventory for selected PCB congeners - a mass balance approach. 3. An update, Sci. Total Environ., 377, 296-307, 2007.

Cabrerizo, A., Dachs, J., Barceló, D., and Jones, K.: Influence of organic matter content and human activities on the occurence of organic pollutants in Antarctic soils, lichens, grass, and mosses, Environ. Sci. Technol., 46, 1396-1405, 2012.

Cornelissen, G., Haftka, J., Parsons, J., and Gustafsson, O.: Sorption to black carbon of organic compounds with varying polarity and planarity, Environ. Sci. Technol., 39, 3688-3694, 2005.

Cousins, I. T. and Mackay, D.: Transport parameters and mass balance equations for vegetation in Level III fugacity models. Internal report published on the website of the Canadian Environmental Modelling Centre, available at: http://www.trent.ca/ envmodel/ (last access: 28 August 2015), 2000.

Cousins, I. T. and Mackay, D.: Strategies for including vegetation compartments in multimedia models, Chemosphere, 44, 643654, 2001.

Daly, G. L. and Wania, F.: Simulating the influence of snow on the fate of organic compounds, Environ. Sci. Technol., 38, 41764186, 2004.

Dewailly, E., Nantel, A., Weber, J.-P., and Meyer, F.: High levels of PCBs in breast milk of Inuit women from Arctic Quebec, Arch. Environ. Con. Tox., 43, 641-646, 1989.

Friedman, C. L. and Selin, N. E.: Long-range atmospheric transport of polycyclic aromatic hydrocarbons: A global 3-D model analysis including evaluation of Arctic sources, Environ. Sci. Technol., 46, 9501-9510, 2012.
Friedman, C. L., Pierce, J. R., and Selin, N. E.: Assessing the influence of secondary organic verus primary carbonaceous aerosols on long-range atmospheric polycyclic aromatic hydrocarbon transport, Environ. Sci. Technol., 48, 3293-3302, 2014a.

Friedman, C. L., Zhang, Y., and Selin, N. E.: Climate change and emissions impacts on atmospheric PAH transport to the Arctic, Environ. Sci. Technol., 48, 429-437, 2014b.

Gioia, R., Lohmann, R., Dachs, J., Temme, C., Lakaschus, S., Schulz-Bull, D., Hand, I., and Jones, K. C.: Polychlorinated biphenyls in air and water of the North Atlantic and Arctic Ocean, J. Geophys. Res., 113, D19302, doi:10.1029/2007JD009750, 2008.

Gouin, T., Armitage, J. M., Cousins, I. T., Muir, D. C. G., Ng, C. A., Reid, L., and Tao, S.: Influence of global climate change on chemical fate and bioaccumulation: The role of multimedia models, Environ. Toxicol. Chem., 32, 20-31, 2013.

Hansen, K. M., Halsall, C. J., and Christensen, J. H.: A dynamic model to study the exchange of gas-phase persistent organic pollutants between air and a seasonal snowpack, Environ. Sci. Technol., 40, 2644-2652, 2006.

Hansen, K. M., Christensen, J. H., Geels, C., Silver, J. D., and Brandt, J.: Modelling the impact of climate change on the atmospheric transport and the fate of persistent organic pollutants in the Arctic, Atmos. Chem. Phys., 15, 6549-6559, doi:10.5194/acp-15-6549-2015, 2015.

Huang, P., Gong, S. L., Zhao, T. L., Neary, L., and Barrie, L. A.: GEM/POPs: a global 3-D dynamic model for semi-volatile persistent organic pollutants - Part 2: Global transports and budgets of PCBs, Atmos. Chem. Phys., 7, 4015-4025, doi:10.5194/acp7-4015-2007, 2007.

Hung, H., Halsall, C. J., Blanchard, P., Li, H. H., Fellin, P., Stern, G., and Rosenberg, B.: Are PCBs in the Canadian Arctic atmosphere declining? Evidence from 5 years of monitoring, Environ. Sci. Technol., 35, 1303-1311, 2001.

Hung, H., Blanchard, P., Halsall, C. J., Bidleman, T. F., Stern, G. A., Fellin, P., Muir, D. C. G., Barrie, L. A., Jantunen, L. M., Helm, P. A., Ma, J., and Konoplev, A.: Temporal and spatial variabilities of atmospheric polychlorinated biphenyls (PCBs), organochlorine (OC) pesticides and polycyclic aromatic hydrocarbons (PAHs) in the Canadian Arctic: Results from a decade of monitoring, Sci. Total Environ., 342, 119-144, 2005.

Hung, H., Kallenborn, R., Breivik, K., Su, Y., Brorström-Lundén, E., Olafsdottir, K., Thorlacius, J. M., Leppänen, S., Bossi, R., Skov, H., Manø, S., Patton, G. W., Stern, G., Sverko, E., and Fellin, P.: Atmospheric monitoring of organic pollutants in the Arctic under the Arctic Monitoring and Assessment Programme (AMAP): 1993-2006, Sci. Total Environ., 408, 2854-2873, 2010.

Kallenborn, R., Christensen, G., Evenset, A., Schlabach, M., and Stohl, A.: Atmospheric transport of persistent organic pollutants (POPs) to Bjornoya (Bear island), J. Environ. Monitor., 9, 10821091, 2007.

Kennicutt II, M. C., McDonald, S. J., Sericano, J., Boothe, P., Oliver, J., Safe, S., Presley, B. J., Liu, H., Wolfe, D., Wade, T. L., Crockett, A., and Bockus, D.: Human contamination of the marine environment - Aurther Harbor and McMurdo Sound, Antarctica, Environ. Sci. Technol., 29, 1279-1287, 1995. 
Koelmans, A. A., Jonker, M. T. O., Cornelissen, G., Bucheli, T. D., Van Noort, P. C. M., and Gustafsson, O.: Black carbon: The reverse of its dark side, Chemosphere, 63, 365-377, 2006.

Lamon, L., von Waldow, H., MacLeod, M., Scheringer, M., Marcomini, A., and Hungerbuhler, K.: Modeling the global levels and distribution of polychlorinated biphenyls in air under a climate change scenario, Environ. Sci. Technol., 43, 5818-5824, 2009.

Li, N. Q., Wania, F., Lei, Y. D., and Daly, G. L.: A comprehensive and critical compilation, evaluation, and selection of physicalchemical property data for selected polychlorinated biphenyls, J. Phys. Chem. Ref. Data, 32, 1545-1590, 2003.

Lohmann, R., Jaward, F. M., Durham, L., Barber, J. L., Ockenden, W., Jones, K. C., Bruhn, R., Lakaschus, S., Dachs, J., and Booij, K.: Potential contamination of shipboard air samples by diffusive emissions of PCBs and other organic pollutants: Implications and solutions, Environ. Sci. Technol., 38, 3965-3970, 2004.

Lohmann, R., MacFarlane, J. K., and Gschwend, P. M.: Importance of black carbon to sorption of native PAHs, PCBs, and PCDDs in Boston and New York, Harbor sediments, Environ. Sci. Technol., 39, 141-148, 2005.

Ma, J., Hung, H., Tian, C., and Kallenborn, R.: Revolatilization of persistent organic pollutants in the Arctic induced by climate change, Nature Climatic Change, 1, 255-260, 2011.

Mackay, D.: Multimedia Environmental Models: The Fugacity Approach, 2nd Edn., Lewis Publishers, Boca Raton, 2001.

Mackay, D. and Paterson, S.: Evaluating the multimedia fate of organic chemics: A level III fugacity model, Environ. Sci. Technol., 25, 427-436, 1991.

Mackay, D., Shiu, W. Y., Ma, K.-C., and Lee, S. C.: Handbook of Physical-Chemical Properties and Environmental Fate for Organic Chemicals, 2nd Edn., CRC Press, Boca Raton, 2006.

Octaviani, M., Stemmler, I., Lammel, G., and Graf, H. F.: Atmospheric transport of persistent organic pollutants to and from the Arctic under present-day and future climate, Environ. Sci. Technol., 49, 3593-3602, 2005.

Park, R. J., Jacob, D. J., Chin, M., and Martin, R. V.: Sources of carbonaceous aerosols over the United States and implications for natural visibility, J. Geophys. Res., 108, 4355, doi:10.1029/2002JD003190, 2003.

Ping, C.-L., Michaelson, G. J., Jorgenson, M. T., Kimble, J. M., Epstein, H., Romanovsky, V. E., and Walker, D. A.: High stocks of soil organic carbon in the North American Arctic region, Nat. Geosci., 1, 615-619, 2008.

Potter, C. S., Randerson, J. T., Field, C. B., Matson, P. A., Vitousek, P. M., Mooney, H. A., and Klooster, S. A.: Terrestrial ecosystem production: A process model based on global satellite and surface data, Global Biogeochem. Cy., 7, 811-841, 1993.

Ribes, S., Van Drooge, B., Dachs, J., Gustafsson, O., and Grimalt, J. O.: Influence of soot carbon on the soil-air partitioning of polycyclic aromatic hydrocarbons, Environ. Sci. Technol., 37, 26752680, 2003.

Roth, C. M., Goss, K.-U., and Schwarzenbach, R. P.: Sorption of diverse organic vapors to snow, Environ. Sci. Technol., 38, 40784084, 2004.
Schenker, U., MacLeod, M., Scheringer, M., and Hungerbuhler, K.: Improving data quality for environmental fate models: A leastsquares adjustment procedure for harmonizing physicochemical properties of organic compounds, Environ. Sci. Technol., 39, 8434-8441, 2005.

Schwarzenbach, R. P., Gschwend, P. M., and Imboden, D. M.: Environmental Organic Chemistry, 2nd Edn., John Wiley \& Sons Inc, Hoboken, NJ, USA, 2003.

Simcik, M. F., Franz, T. P., Zhang, H. X., and Eisenreich, S. J.: Gasparticle partitioning of PCBs and PAHs in the Chicago urban and adjacent coastal atmosphere: States of equilibrium, Environ. Sci. Technol., 32, 251-257, 1998.

Smith-Downey, N., Sunderland, E., and Jacob, D.: Anthropogenic impacts on global storage and emissions of mercury from terrestrial soils: insights from a new global model, J. Geophys. Res., 115, G03008, doi:10.1029/2009JG001124, 2010.

Sobek, A. and Gustafsson, O.: Deep water masses and sediments are the main compartments for polychlorinated biphenyls in the Arctic Ocean, Environ. Sci. Technol., 48, 6719-6725, 2014.

Stocker, J., Scheringer, M., Wegmann, F., and Hungerbuhler, K.: Modeling the effect of snow and ice on the global environmental fate and long-range transport potential of semivolatile organic compounds, Environ. Sci. Technol., 41, 6192-6198, 2007.

Su, Y., Hung, H., Stern, G., Sverko, E., Lao, R., Barresi, E., Rosenberg, B., Fellin, P., Li, H., and Xiao, H.: Bias from two analytical laboratories involved in a long-term air monitoring program measuring organic pollutants in the Arctic: a quality assurance/quality control assessment, J. Environ. Monitor., 13, 31113118, 2011.

von Waldow, H., MacLeod, M., Jones, K., Scheringer, M., and Hungerbühler, K.: Remoteness from emission sources explains the fractionation pattern of polychlorinated biphenyls in the northern hemisphere, Environ. Sci. Technol., 44, 6183-6188, 2010.

Wania, F. and Mackay, D.: Global fractionation and cold condensation of low volatility organochlorine compounds in polar regions, Ambio, 22, 10-18, 1993.

Wania, F. and Mackay, D.: Tracking the distribution of persistent organic pollutants, Environ. Sci. Technol., 30, A390-A396, 1996.

Wild, S., McLagan, D., Schlabach, M., Bossi, R., Hawker, D., Cropp, R., King, C. K., Stark, J. S., Mondon, J., and Bengtson Nash, S.: An Antarctic research station as a source of brominated and perfluorinated persistent organic pollutants to the local environment, Environ. Sci. Technol., 49, 103-112, 2015.

Wornschimmel, H., MacLeod, M., and Hungerbuhler, K.: Emissions, fate and transport of persistent organic pollutants to the Arctic in a changing global climate, Environ. Sci. Technol., 47, 2323-2330, 2013.

Zhao, Y., Huang, T., Wang, L., Gao, H., and Ma, J.: Step changes in persistent organic pollutants over the Arctic and their implications, Atmos. Chem. Phys., 15, 3479-3495, doi:10.5194/acp-153479-2015, 2015. 